\title{
Stoflike versorging in die Nuwe Testamentiese Kerk - waarheen lei dit ons in ons ondersoek na die diakenamp?
}

In 'n vorige artikel (gepubliseer in In die Skriflig. No. 4, Aug.Sept. 1967) het enige op die oog af direkte gegewens omtrent die Diakenamp in die Skrif ondersoek. t.w.

1. Handelinge 6 en die Diakenamp:

2. Die begrip ..diakonos" as aanduiding van "n besondere ampsdraer.

Die resultate daarvan was hoofsaaklik negatief, in dié sin dat bevind is dat uit hierdie gegewens weinig konkreets oor die diakenamp gesê kan word.

Hierdie studiestuk poog om in saaklike ondersoek in te stel uitgaande van sekere hedendaagse beskouinge van die diakenamp. die Skrifgegewens daaromtrent na te speur en vas te stel waarheen dit ons mag lei in die nadere bepaling van die diakenamp.

1. Die Besondere andag ran die Evangelie an die armes en die weduwees:

Wie aan die diaken dink. dink onmiddellik aan die armes en die weduwees.

Die besondere aandag wat die Evangelie van Christus (én die O.T.!) aan die armes en die weduwees gee, is goed bekend.

Ons volstaan met 'n verwysing na in verteenwoordigende aantal kernuitsprake oor die armes en die weduwees.

Armes:

L.ukas 6:20 - Salig is julle. armes . . . .

Matth. 11:5

l.uk.

l.uk.

$7: 22$

Mark. 10:17.31 par.

l.uk.

$14: 12.14$

l.uk. 16:19.25

l.uk. 19:8

1 Tim. 6:17.19

Jak. 5:1.6

Hand. $2: 42 \cdot 47$

Hand. 4:32.37

Hand. 11:29.30)

Hand. 24:17

Rom. 15:25.31

1 Kor. 16:1.4

2 kor. 8 en 9

(ial. 2:10

I.uk. $21: 1.4$

Jak. $2: 1.13$
Die evangelie aan die armes - hoe wesentlik dit is: dit is merkteken van die ware Messias.
Die eis van mededeelsaamheid van die rỵke met die arme.

Die gemeenskaplike besit in die vroegste kerk. sodat niemand behoeftig was nie.

Die stoflike gemeenskap wat die gelowiges uit die heidennasies moes hê met die hehoeftige gemeente van Jerusalem.

Dat in die gemeente geen onderskeid tussen ryk en arm gemaak mag word nie. 
Wedurees:

Mark. 12:40 par. - Jesus veroordeel die Farisieërs wat ..die huise van die weduwees opeet".

Mark. 12:41.44 par. - Jesus stel die arm weduwee se gawe as voorbeeld.

Luk. 7:12 - Jesus ontferm Hom oor die treurende weduwee.

Hand. (0:1.7 - Die Griekssprekende weduwees en die daaglikse diakonia.

Hand. 9:39-41 - Belangrik vir die plek van die weduwees in die gemeente.

1 Tinı. 5:1.16 ... Oor die versorging van weduwees.

- en oor die verkiesing van 'n weduwee.

Jak. 1:27 - Hoogwaardering van besoek aan weduwees en wese.

2. Is die henaming "Diens van Barmhartigheid" as aanduiding van die armversorging in die Nawe Testamentiese Kerk Skrifnurlik verantwerorl?

In ons kerklike lewe dra die amp van die diaken lank reeds dic geykte beskrywende naam: die diens van barmhartigheid.

Onder .diens van barmhartigheid" word dan verstaan: die kerklike versorging van die hulpbehoewendes: die stoflike versorging van armes. En dit word dan gesien as die ampswerk van die diaken.

l.aat ons nou in volgorde nader besien:

(a) Die vraag of versorging van die behoeftige gelowiges Skriftuurlik omskryf kan word as harmhartigheidsdiens.

(b) Die vraag of daar in die N.T. verband is tussen die begrip ..barmhartigheid" en die begrippe diakonia/diakonos.

(a) Is daar "n suaklike verhand mssen die hegrippe "harmhartigheid" en "armversorging" in die N.T.

(i) Die Begrip harmharrigheid in die N.T.:

Die N.Tiese begrippe vir ..barmhartigheid" is eleos - eleeō elếmosunê. Selde ook: oiktirmos - oiktirmön.

Die grondgedagte van die eleos-begrip is dié van ontroering. mede. lyde met die ellendige.

Die Hebreeuse begrip was chesed.

Chesed kan tweërlei betekenis hê:

(a) pligmatige trou. bv. die tussen familie of bondgenote - in dic betekenis in L.XX. vertaal as: dikaiosune.

(b) Hulp, goedheid, genade van in hoër geplaasde teenoor sy mindere of die ellendige - Ján in I.XX vertaal as eleos."

Die grondgedagte van eleêmosune, 'n laat.(jriekse woord. is ook: medelyde.

In die LXX is dit meestal die vertaling van die Hebreeuse sedaka.

Seduku kan ook tweèrlei betekenis hê:

(a) geregtigheid - dán in $1 . X X$ vertaal met dikaiosunê. 
(b) goedertierenheid. weldadigheid. genade: in besonder: weldadig. heid teenoor die armes $=$ aalmoes - dan in LXX vertaal as electmosunê.

Beide eleos (as vertaling van chesed) en elếmosumê (as vertaling van seduka) het gevolglik tweërlei betekenis:

(a) die (joddelike erbarning; Gods neerbuigende, helpende liefde.

(b) menslike erbarming: besonderlik: barmhartigheidsbeoefening. milddadigheid teenoor die nederige. ${ }^{2}$

Dic verskil in gebruik was dat eleos meestal die algemene term is, cn eleêmostmê die meer besondere. t.w. spesifick die weldaad aan dic armes.

Eleos slaan dus in die N.T. nie noodwendig op barmhartighed aan armes nie. Daarenteen word poiein elếmosune legniese term vir dic loodse ..barmhartigheid bewys". d.w.s. ..hulp aan die arme" of ..aalmoese gee".

In die N.T. word elé̂mosumê inderdaad alleen van menslike neerhuigende genade gebruik en beteken .,aalmoes" as "n daadwerklike barmhartigheid.

(ii) Dic admoes-gedagte hy die Jode in die N.T.

('it die Rabbynse literatuur blyk dat die gee van aalmoese in die Joodse godsdiens van die N.Tiese tyd eintlik gelyk gestaan het aan gebodsvervulling. en dan wel die hooîgebodsvervulling. Die gee van gawes aan die ellendiges deur die indiwidu is besonder hoog aange. slaan. Die koste van die gemeenskaplike armversorging is uit in tempelbelasting gedek, waartoe die gemeentelede verplig was na gelang van hulle prestasievermoë. Daarnaas kon egter vrywillige indiwiduele gawes aan die armes gegee word. ${ }^{3}$

lets van hierdie klem wat dic barmhartigheids- of aalmoesbegrip in die Ioodse godsdiens gehad het. kry ons ook weerspieël in die Evangelie: Jesus laat in sy gesprekke met die Skrifgeleerdes en Farisiërs dikwels die nadruk val op die regte wyse van en regte gesindheid by die gee van aalmoese (vgl. o.a. Malth. 6:2-4: I uk. 11:4l: Luk. 12:33). Ook benadruk Jesus op meer algemene wyse, juis met die gebruik van cleos of ele'os. die noodsaaklikheid van die barmhartigheidslewe tcenoor die naaste (vgl. Matth. 5:7; Matth. 9:13: Matth. 12:7; Matth. 23:23: I.uk. 10:37).

Daarteenoor is dit opvallend dat. spesifiek met betrekking tot die versorging van die behoeftiges in die gemeente. die aulmoeshegrip. wat so baie gewig dra in die Joodse godsdiens. nie prominemt is in die N.Tiese gerneentelike len'e nie!

In I/andelinge. waar die gemeentelike lewe van die vroegste kerk geteken word. en waar die aangeleentheid van stoflike besit en armoede in Hand. 2.4 skerp benadruk word. word die aalmoesbegrip nie vir die versorging van die behoeftes van die gelowiges gebruik nie. 
Die kreupel $J(o x d$ vra die apostels wel on 'n aalmoes (Hand. 3:2. 10); en van die proseliet Cornelius se lewe voor sy bekering word vermeld sy baie aalmoese wat hy aan die volk (Jode) gegee het. Verder verwys Paulus ook wel eenmaal na die bydraes van die gemeentes vir Jerusalem as .,aalmoese en offers aan my volk" (Hand. 24:17). In die lig van sy woordgebruik in sy briewe met betrekking tot dié saak (sien hieronder), moet egter aangeneem word dat Paulus hom hier aanpas by die spraakgebruik van sy Joodse teëstanders in die hofgeding voor Felix.

Die enigste uitsondering is Hand. 9:36, waar van Talita gesê word: ..sy was oorvloedig in goeie werke en aalmoese wat sy gedoen het".

In die briewe lan Paulus ontbreek die begrip aalmoes geheel en al. Paulus gebruik wel eleos en eleeó dikwels, maar feitlik deurgaans net in verband met (jod se barmhartigheid teenoor die mens in sy ellendige sondestaat.

Die uitsondering hier is Rom. 12:8, die bekende en belang. wekkende uitspraak oor die charismata in die gemeente: .. wie barmhartigheid bewys, met blymoedigheid".

Waar Paulus egter uitdruklik handel oor die versorging van die armes in die kerk. plaaslik en in kerkverband, soos in 1 Tim. 5: Rom. 12:13: Rom. 15:25.31; I Kor. 16:1.4: 2 Kor. 8.9. spreek hy in ander begrippe as die aalmoes. of barmhartigheidgedagte.

Ook in die Algemene Sendhriewe kom eleĉmosunê nie voor nie. terwyl eleos alleen deur Jakobus gebruik word, en wel twee maal: in Jak. 2:13 as samevatting van die gesindheid en gedrag van die gemeente teenoor die ryke en die arme, en in Jak. 3:17 saam met ander christelike deugde.

\section{Slotsom:}

Ons moet dus konkludeer dat die aalmoes-gedagte van die Joxledom nie die beheersende gedagte by die versorging van die behoef. tiges in die N.Tiese kerk was nie; ja, ook breër gestel: dat ook die barmhartigheidsgedagte nie prominent was daarby nie.

Om dus die versorging van behoeftiges, weduwees en wese in die christelike gemeente te noem ..die diens van barmhartigheid" vind weinig grond in die N.Tiese kerk.

(b) "Barmhartigheid" en die hegrippe diakonia/diakonos.

Hieroor kan ons kort wees.

In die N.T. is daar bykans geen begripsamehang lussen .,barmhartigheid" en ..diens" (diakonia of diakonos) nie.

Die tegniese term, eleêmoxunê. word nooit saam mel diakonial diakonos gebruik nie.

Slegs eenkeer word diakomia en eleos saam gebruik, nl. in Rom. 12:7 en 8 waar hulle sonder direkte verbanci naas mekaar voorkom. 
In 2 kor. 4:1 word eleeo en diakonia wel in samehang gebruik. maar daar gaan dit on die barmhartigheid van Giod waardeur Paulus in die diakonia ran die apostelskap staan!

Slotsom:

(jeoordeel op sprackgehruik in die N.T.. is daar nie grond on die amp van die diaken te omskryf as die diens van barmhartigheid nie.

3. Die noue samehumg ran die hegrippe: arm (hehoefrig ens.) en koinomia (gemeenskap).

Die primêre koinomia (gemeenskap) in die N.T.' is geestelik van aard: gemeenskap met Jesus Christus. sy dool en opstanding. sy (iees, deur die geloof.

Die geestelike koimmia met Christus en al sy gawes, lei na die apostoliese getuienis egter noodwendig tot 'n openbaring van koinomia tussen die gelowiges: die gelowiges het gemeenskap met mekaar deur hulle gemeenskaplike gemeenskap met Christus. ..Die Christusgemeinschaft führ notwendig über in die Christengemeinschaft. die Gemein. schaft der Glieder untereinander":

Nou het koinomia na sy grondbetekenis in sterk aktief-konkrete konnotasie: dit is ..gemeenskap" in die sin van

(i) met ienand deel he aan iets:

(ii) 'n aundeel neem aan iets:

(iii) iemand deelname gee aan iets.

En nou is dit opvallend hoedat in die Nieu-Testamentiese kerk juis hierdie aktief-konkrete konnotasie van die begrip die klem dra in die gemeentelike lewe: dit tree veral aan die lig in die besonder opvallende gebruiksamehang tussen die verskillende begrippe vir ..arm" en die begrip koinomia - 'n samehang wat nie in die Evangelie voorkom nie. maar juis opduik onmiddellik na die aanvang van N.Tiese kerk.

In die Jerusalemse gemeente.

Hand. 2:42.47.

Hand. 2:42 stel. onmiddellik by die aanvang van die N.Tiese kerk. voor ons dic vier grondpilare waarop die gemeentelike lewe van die vroegste kerk gebou was: ..En hulle het volhard in die leer van dic apostels en in die gemeenskap en in die breking van die brood en in die gebede".

En dan is die opvallende van die gebruik van die woord hier. dat dit duidelik in in heel besondere betekenis gebruik word. In bree sin sluit koinomia al drie die ander sake in: leer van die apostel (precliking): breking van die brood (nagmaal): gebede - dit is die uitinge van die gemeente se gelonfgemeenskap! Maar hier word komomia onderskei van genoemde sake en daarnaas geplaas. Dit is $\mathrm{n}$ aanduiding dat koinumia hier in heel hesondere. gekonsentreerde. slerk konkrete betekenis moes aanneem. 
Vers 44 keer dan ook spesifick hierna terug: ..En almal wat gelowig geword het. was hymekaar en het alles gemeenskaplik hesit (koina!). Dit is dan waarin die konkrete koimonia van die gemeente hestaan: dit is tweeledig. 'n saum-lewe en 'n gemeenskaplike hesit van curdse goedere, as konkrete belewing van hulle geestelike goedere. nl. die gemeenskap met Jesus Christus.

Vers 45 toon die praktiese betekenis van die koinomia: daar is dan aan elkeen uitgedeel volgens sy behoefte (chreia -. nood of armoede).

Slotsom:

Voorsiening in die hehoeftes l'all clke gelowige is hier 'n besonderc belewing van die gemeenkap in die kerk van (hristus, en raak in wesenstrewe van die gemeentelike lewe.

Iland. 4:32.35.

Dieselfde verbande word hier belig:

Vers 32: Die gelowiges het in diepc gerestelike gencenskup geleef (..een van hart en siel"). en dit in komkrete gemeenkap heleef (..niemand het gesê dat iets sy eie was nie. want hulle het alles in gemeenskap (koina) gehad").

Verse 34 en 35 toon dic praktiese betekenis van hierdic koinomia. Niemand van die gemeente was arm (endeês) nie. want aan elkeen is mitgedeel volgens sy behoefte (chreia).

Rom. 12:13 ...Neem 'n aandeel aan" of ..Beoefen gemeenskap met" (ksinōneö) die behoeftes (chreiai) ..van die heiliges".

I.et wel: Hier word die begrip ..gemeenskap" reeds 'n daadwerk. like hulpbetoon in die armoede van die deelgenote van die geloof!:

In Paulus se kollekte vir die gemeente ian Jerusalem.

Besonder prominent is die samehang tussen koimonia en die .armoede"'begrippe in die gedeeltes wat op hierdie saak betrekking het:

2 Kor. 8 en 9.

In 2 Kor. 8 word korinomia (vs. 4) in noue verband gebruik met ptöcheia (armoede -- vs. 2 en 9): ptöcheuō (arm wees vs. 9) en hustérema (gebrek of tekort - vs. 14). Dit gaan on die bydraes aan die behoeftiges van gemeentes van Jerusalem en/of die behoeftige gemeente self. Hierdie bydrae noem Paulus: churis (liefdegawe. guns) en eulogia (dankoffer). En nou gebruik Paulus korimonia as ekwiva. lent hiernaas.

$\mathrm{Om}$ ' $\mathrm{n}$ liefdegawe. 'n dankoffer aan die armoedige ..heiliges". gelowiges van Jerusalem te skenk. is om gemeenskap te beofen met die behoeftige medegelowiges.

In 2 Kor. 9 word koinomia saam mel peness (arn - vs. 9) en husterêma (gebrek - vs. 12) gebruik. 
Paulus getuig hier dat die voorsiening in die behoeftes van die heiliges vir hulle bewys is van: (i) .die onderwerping aan julle bely. denis" en van (ii) mildadige gemeenskapsbeoefening met hulle.

Rom. 15:25-3I - ..Want Macedonië en Achaje het dit goed. gevind on 'n sekere koinomia te maak aan die armes (ptöchoi) van die heiliges in Jerusalem".

Hier word die begrip ..geneenskap" reeds tot so "n mate vereenselwig met .,armversorging" dat koinomia hier tereg met die konkrete betekenis van ..kollektes" of ..bydrae" vertaal kan word: ..Das Ab. straktum koinomia wird dem Paulus darüber R15.26 unmittelbar zum Konkretum Kollekte".

Besonder belangrik is hier Paulus se fundering en motivering van die hydrae van die christene uit die heiden volke vir die arm gemeente van Jerusalenı: ..Want as die heidene gemeenskap gekry het (koinmeö) aan hulle (die Jode se) geestelike goedere, is hulle ook verskuldig om hulle met stoflike goedere te dien" (vs. 27).

Die heidenchristene het gemeenskap gekry aan die geloof van die Joodchristene, hoe kan dit dan anders as dat hulle stoflike gemeen. skap met die Jookdchristene beoefen deur hulle in hul armoede te hulp te kom!

\section{(ial. 2:9.10).}

By die duidelike terreinverdeling tussen die apostels onder die Ioxle en dié onder die heidene. gee hulle mekaar egter die regterhand van gemeenskap (koinomia). En dan volg direk die opvallende be. paling: alleen moet Paulus en Barnabas dan onder die heidenchristene dink aan die ptöchoi (die armes - scil. van Jerusalem!).

Dáárin sal - na hulle klaarblyke gevoel -- die koinonia op heerlike wyse geopenbaar word!

Ek verwys ook na Hehr. 13:16 en I Tim. 6:18 vir soortgelyke verbinding ..armversorging" aan die kernbegrip koinomia.

In die versorging van die hedienaurs van die Word.

ril. 4:10.20.

Hier word sunkorineō en koinomeo verbind aan Paulus se persoonlike behoeftes, uitgedruk met die terme: husterésis (gebrek --- vs. 11). chreia (behoefte - vs. 16) en thlipsis (verdrukking - vs. 14). Hy stel dit egter ook breër: aan sy hele ..rekening van uitgawe en inkomste"'!

(jal. 6:6 hang ten nouste hiermee saam: ..Maar laat hom wat in dic Woord onderwys ontvang. gemeenskap gee (koinomeö) in alle greic dinge aan hom wat onderwys gee".

Hier het ons ook in verband met die versorging van die bedienaar van die Woord dieselfde wisselwerking van die koinomia in geestelike en in stoflike goedere as wat ons in Rom. 15:25.31 gehad het in verband met die versorging van die behoeftige broeders! 
(ievolgtrekking:

(i) Voorsiening in die behoeftes van die geloofsgenote (armver. sorging) is in die N.T. ten nouste verbonde met die wese van kerk.wees.

(ii) Maar hierdie .armversorging" is nie "n opsigself staande saak in die kerk nie. Dit is deel van 'n groter en diepergaande saak: die konkrete belewing en uitlewing van die gemeenskap van die geloof deur een Gees.

(iii) Hierdie konkrete gemeenskap kon op gelykluidende wyse tot uitdrukking in die stoflike versorging van die bedienaar van die Woord.

4. Samehang van die hegriple .gemeenskap" e'n, ,versorging l'an die hehoeftiges" met die hegrip diakomia.

$1 /$ Korinthiërs 8 en 9.

Die begrip diakomia kom in hierdie twee hoofstukke oor die kollekte vir die behoeftige gemeente van Jerusalem nie minder nie as ses keer voor: vier keer diakomia en twee keer die deelwoord: diaks. noumenei.

In 2 Kor. 8:1.5 gaan dit oor die hydrae van die kerke van Mace. donië.

Nieteenstaande hulle eie diepe armoede (vers 2) was hulle bereid. nee begerig. on bo hulle vermoe by te dra (vers 3). en het gesmeek dat aan hulle geleentheid gebied word vir ., $n$ liefdegawe (of guns charis) en gemeenskap (koinomia) aan die bediening (diakomia) aan die heiliges" (vers 4).

Hier is dus prake van in diakonia. in BEDIENIN(;. waardeur liefdegawes aan die heiliges, d.i. aan die geloofsgenote dic gemeente van Jerusalem) geskenk word. en waardeur stoflike. konkrete gemeen. skap met die geloofsgenote beoefen word.

Temeer belangrik word hierdie uitspraak van vers 4 wanneer die genetief. tês diakonias, saam met Grosheide" geneem word as genitivus explicatus by charis en koinomia.

Dan sê Paulus hier: die Macedoniers wou graag in liefdegawe gee en gemeenskap bestaan wat sol hestaun in bediening van die heiliges. ..Daardoor wordt de diakomia gekenschetst als charis en als koinumia".

En dan het ons hier sprake ran 'n BEDIENING; wat behels: liefdegaw'e en konkrete gemeenkapsheofefening met hehoreftige geloofsgenote!

Van groot belang is verder om hier nou te wys op Paulus se konsekwente gebruik van die benaming hagioi, heiliges vir die gelowiges van Jerusalem in sy spreke oor hierdie BEDIENIN(;.

Ek haal Ridderbos se treffende uitspraak hieroor aan:"

..De praegnantie van hoi hagioi als armen zal daarom speciaal te zooken zijn in de verbinding van begrippen als diakomein. kommia. koinonej, logecia enz. met hoi hagiori ... m.a.w. het specifieke spraak. 
gebruik stempelt niet sozeer de heiligen als atmen. maar de DIENST. COI.I.EKTE enz. als een dienst aan de heiligen van God, d.w.z. als onderling CHRISTELIJK hulpbetoon. Het is niet slechts een dienst van aalmoezen of van algemene menslievendheid; het is een dienst die. omdat hij aan de heiligen Gods geschiedt. ook zelf een hoog en heilig karakter draagt. en daarom met des te grotere bereidwilligheid ver. vuld wil worden."

Opvallend is dat Ridderbos ook langs hierdie weg kom by die afwysing van die aalmoes-(barmhartigheids-) gedagte as grond vir die kerk se bediening aan die hehoeftiges. Verder toon ook hierdie gebruik van Paulus dat hierdie bediening gesien word as geloofsdaad wesentlik eic aan die volk van God.

In 2 Kor. 8:19.20 is weer sprake van hierdie liefdegawe (charis) wat deur ons bedien word (diakomoumenêi)" en van hierdie oorvloed (hadrotês) wat deur ons bedien word (diakomoumenêt).

In 2 Kor. 9:1.9 roep Paulus die Korinthiërs op tot ..die bediening (diakomia) aan die heiliges". Hulle gawes noem hy in verse 5 en 6 in dankoffer (eulogia). en in vers 9 sluit hy sy oproep tot hulle af met die woorde: ...Soos geskrywe is: Hy het uitgestrooi. hy het dan die armes (penêsin) gegee. sy geregtigheid bly tot in ewigheid".

In 2 Kor. 9:12.15 getuig Paulus van die hetekenis wat hierdie bediening vir die geloofgenote in Jerusalem sal hê:

(ii) Die bediening (diakomia) van hierdie dienswerk (leitourgia) voorsien in die behoeftes (husterêtnata) van die heiliges (vers 12). Maar nie alleen dit nie. ook is hierdie bediening vir dic Jerusalemse geloofsgenote;

(ii) die bewys van die Korinthiërs se onderwerping van hulle belydenis aan die Evangelie (d.w.s. die bewys dai hulle hulle geloof waarlik wil beleef en uitleef);

(iii) asook die bewys van hulle milddadige gemeenskap met die gelowiges van Jerusalem en met almal!

\section{Romeine 15:25.31.}

Hier gebruik Paulus sowel die werkwoord diakomeo (vers 25) as die snw. diakonia (vers 31) om sy insameling van Macedonie en Achaje se gemeenskapsgawe (koinomia ... vers 26 ) en die uitdeling daarvan aan die behoeftige heiliges in Jerusalem aan te dui.

Vers 27 toon dat Paulus hier pertinent onderskeidend spreek. Hy gebruik naamlik hier twee woorde vir ..dien": leitourgeó en diakomeó. Die ander gemeentes het in plig on die Jerusalemse gemeente met stoflike goedere to dien (leitourgeö). terwyl Paulus reis on hierdie koinonia. hierdie gemeenskapsgawe aan die Jerusalemse gemeente te gaan hedien Idiakomeō).

Verder onderskei Paulus geestelike goedere en stoflike goedere: Dit is die wesentlike geloofsplig van die gemeentes van Macedonic en Achaje om waar die Joodse gemeente hulle gemeenskap gegee het 
aan hulle geestelike goedere, nou die Jerusalense gemeente met hulle stoflike goedere te dien (leitourgeō). Paulus, wat die hele dangeleentheid organiseer, propageer en beheer, hedien (diakomeō).

Hier skyn Diakonia werklik reeds hyna tegniese term te word: die BEDIENING van stoflike gemeenskapsgawe an 'n hehoeftige gemeente en/of die hehoeftiges van die gemeente. wardeur die geloofs. gemeenskap konkreet beleef word.

2 Kor. 9:12 in die lig hierwan weer besien.

Hier kry ons $\mathrm{nl}$. dieselfde onderskeiding: ..want die bediening (diakonia) van hierdie dienswerk (leitourgia) voorsien nie alleen in die behoeftes van die heiliges nie".

In die lig van Rom. 15:25.31, moet leitourgia hier verstaan word as die .diens deur stoflike goedere" van die Korinthiërs, en diakonia as Paulus c.s. se hediening daarvan aan Jerusalem, as die gesante van die gemeentes vir dié doel.

Handelinge 11:29.30 en 12:3511

Dit is besonder opvallend dat die skrywer l.ukas in hierdie Skrif. gedeeltes in presies dieselfue terme oor die kollekte vir Jerusalem spreek as wat Paulus dit in Rom. 15:31 doen.

Hand. 11:29.30: ..En die dissipels het besluit dat iedereen van hulle na sy vermoë sou stuur tot hediening eis diakomia) van dic broeders wat in Jerusalem woon. En dit het hulle gedoen en dit deur Barnabas en Saulus aan die ouderlinge gestuur."

Hand. 12:25: En Barnabas en Saulus het van Jerusalem terug. gekeer, nadat hulle die bediening (tên diakoniun) vervul het."

Cievolgtrekkinge:

(1) Daar is 'n opvallende herhaaldelike gebruik van diakonia in ver. band met die liefdesdiens en gemeenskapsbetoon in stoflike goedere aan behoeftige geloofsgenote.

(2) Hierdie diakonia is te karaktiseer as: gemeenskapsbelewing met of betoning aan die heiliges, hulle met wie die ander gelowiges gemeenskap aan geestelike goedere het.

(3) Gevolglik is hierdie diakonia duidelik 'n wesentlike saak vir die ware kerk-wees van die gemeente.

(4) Tog is diakonia/diakomeo in die behandelde gedeeltes na alle waarskynlikheid nie as tegniese term ( diakonale sorg) gebruik nie. (Temeer so ook in die lig van die ruimere gebruik van hierdie begrippe deur Paulus vir enige dienswerk in die kerk sien my studiestuk oor die begrip diakonos in: In die Skriflig. Aug.Sept. 1967.) D.w.s. selfs in Rom. 15:25 beteken diakomeó nie: .die werk van "n diaken doen" nic.

(5) Andersyds is dit ook duidelik uit die samehang van die begrippe arm-geneenskap-diakonia (soos aangetoon), dat sowel die engere 
saak van armversorging. as dic breère en diepergaande saak van die konkrete gemeenskapsbelewing onder die gelowiges ten duide. likste aangedui word as in besondere en uiters belangrike $B E$. DIENING. En wel as 'n eiesoortige bediening naas andere soos die diakomia van die apostel (0.a. Hand. $21: 19$ ) of van die evangelis (2 Tim. 4:5): vgl. ook 1 Kor. 12:5).

(6) Hoewel dus nie tegniese term in die sin van ..die diakenamp" nie. kry diakonia of pllekke soxs Rom. 15:25-31 (en miskien 2 Kor. 9:12: Hand. 11:29: Hand. 12:25) wel 'n sekere tegniese hetekenis, nl.: die hediening ran stoflike gemeenskapsgawes aan 'n hehweftige gemeente en/of die hehoefriges ran die gemeente, wardeur die geloofsgemeenskap konkreet heleef word!'

Naskrif:

Verdere studie voortboucnd op die voorafgaande. sal aandag moet skenk aan o.a.:

1. Afsondering van manne spesiaal vir verskillende vorme van stoflike versorging.

2. Ilitsprake oor dic gemeente en die weduwees.

3. Hand. 6. hesien in die lig van hierdie gegewens.

\section{VOETNOTE:}

I. Vgl. R. Bultmann. Theol. Worterbuch zum N.T. (TWNT). II. 474 e.v.

2. Vgl. Strack-Billerbeck. Kommentar zum N.T., Matthäus, 387 e.s.

3. Vgl. Strack-Billerbeck, a.1... 387-388.

4. Vgl. F. Hauck, koimomia, TWNT III. 804-808 vir in volledige behandeling lan dic leologiese draag "ydte van dic koinomia-begrippe.

5. Hauck. a.w.. 807-808.

6. $\mathrm{Vgl}$. oor Hand 2:42 veral dic prikkelende behandeling deur L. Floor. in dieselfde spore. in Ondersoek na die strukluur van die sendinguerk. 61-68.

7. Vgl. Hauck. a.W.. 808.

8. Hauck. a.w., 809. Vgl. ook H. Ridderbos. Aan de Romeinen. Commentaar op het N.T.. 337.

9. F. W. (irosheide, De Tweede Brief aan de Kerk te Korinthe. Commentaar op het N.T., 226.

10) II Ridderhos. Aan de Romeinen. Commentaar op hel N.T. 336.

II $V_{g} 1 . H$ W. Bejer se slotopmerking oor dirthomia. IWNT II. 88. 